Proceedings of the International Symposium on Physics of Materials (ISPMA 14), September 10-15, 2017, Prague

\title{
Transmission Electron Microscopy Study of Microstructure Evolution of Al-Mg-Sc Alloy after Annealing at $120^{\circ} \mathrm{C}$
}

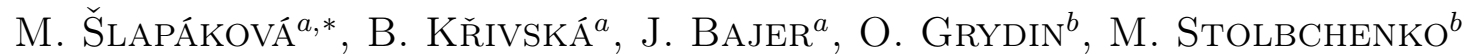 \\ AND M. CIESLAR ${ }^{a}$ \\ ${ }^{a}$ Charles University, Faculty of Mathematics and Physics, Department of Physics of Materials, \\ Ke Karlovu 5, 12116 Prague 2, Czech Republic \\ ${ }^{b}$ University Paderborn, Faculty of Mechanical Engineering, Lehrstuhl für Werkstoffkunde Microscopy, \\ Pohlweg 47-49, 33098 Paderborn, Germany
}

The Al-Mg-Sc alloys are used in aerospace and ship-building industry due to their good mechanical properties such as corrosion resistance, weldability and possibility for superplastic forming. Addition of Sc with $\mathrm{Zr}$ may further lead to enhancement of their performance by precipitation of coherent particles of $\mathrm{Al}_{3}(\mathrm{Sc}, \mathrm{Zr})$ phase which are known to stabilize the microstructure and hinder the recrystallization. The role of the material processing on the microstructure and mechanical properties evolution was studied by means of transmission electron microscopy, scanning electron microscopy and resistivity measurement. The Al-Mg-Sc-Zr alloy was manufactured by two different manners - conventional casting and twin-roll casting and subjected to deformation by equal-channel angular pressing. The shape and nature of the grains significantly influenced precipitation of $\beta$-phase $\mathrm{Al}_{3} \mathrm{Mg}_{2}$, which may be detrimental for such kind of materials in the terms of corrosion resistance. The worst properties exhibited the conventionally cast and rolled material with a pancake grain structure where the $\beta$-phase particles forms as continuous layer along the (sub)grain boundaries.

DOI: 10.12693/APhysPolA.134.871

PACS/topics: 81.05.Bx, 81.40.Cd, 81.40.Ef, 81.40.Rs, 61.72.Ff

\section{Introduction}

Al-Mg alloys are widely used in transportation industry due to their high strength, good formability and weldability and favorable corrosion resistance [1-4]. However, addition of more than $3 \mathrm{wt} . \% \mathrm{Mg}$ can cause magnesium to preferably diffuse to the (sub)grain boundaries and form $\beta$-phase $\mathrm{Al}_{3} \mathrm{Mg}_{2}[5,6]$, which is more susceptible to the corrosion than the Al-Mg matrix, and sensitization - intergranular corrosion and stress corrosion cracking - may occur at low and moderate temperatures, leading to exfoliation corrosion [7]. The $\beta$-phase can form either continuously or discontinuously along the (sub)grain boundaries or near the pre-existing Mn-rich particles. The influence of the boundary character on the $\beta$-phase formation is not yet fully understood [8]; however, the structure with elongated (sub)grains is more prone to the $\beta$-phase precipitation [9].

The strength of Al-Mg alloys may be enhanced by addition of elements such as scandium and zirconium $[3,10]$. After suitable heat treatment these form coherent metastable precipitates of $\mathrm{Al}_{3}(\mathrm{Sc}, \mathrm{Zr})$ phase which contribute significantly to the precipitation strengthening and stabilize the microstructure at elevated temperatures due to hindering the motion of dislocations and grain boundaries $[7,11]$.

\footnotetext{
* corresponding author; e-mail slapakova@karlov.mff.cuni.cz
}

Another way how to modify the performance of aluminium alloys is deformation strengthening - achieved e.g. by severe plastic deformation (SPD). One of the most common representatives of SPD is equal-channel angular pressing (ECAP) which may reduce the grain size of the material into micrometric scale and increases thus the strength of the material [12].

Aluminium alloys for sheet production are commonly prepared by direct-chill casting which is followed by several steps of rolling and annealing. Such procedure is energy and material consuming and produces microstructure with elongated grains which is unfavorable in the terms of $\beta$-phase formation and exfoliation corrosion [8]. The elongated structure could be partially removed by recrystallization treatment; however, such is not desired as the elevated temperatures would beside the recrystallization lead also to the coarsening of $\mathrm{Al}_{3}(\mathrm{Sc}, \mathrm{Zr})$ particles, which would transform to the stable state and thus loose their strengthening effect. One of the possibilities how to handle this situation is a use of a different casting technique producing sheets with equiaxed grains and homogeneous microstructure. One of such techniques is twin-roll casting (TRC) where a molten metal is directed between two water-cooled rolls, where it directly solidifies and forms a sheet with thickness of several mm $[13,14]$. However, the different casting procedure leads to a different initial microstructure - e.g. density, size and distribution of primary particles, solid solution supersaturation, formability behavior $[15,16]$. Thus, the routes developed for treatment of conventionally cast (CC) materials have to be modified to achieve comparable material performance for the material prepared by TRC [17, 18]. 
In the recent study we compare the microstructure and formation of $\beta$-phase in an Al-Mg alloy enhanced by the addition of $\mathrm{Sc}$ and $\mathrm{Zr}$ in the terms of casting route conventional casting and twin-roll casting, the later one further followed by deformation by ECAP.

\section{Experimental}

Aluminium alloy with the main alloying elements 3.24 wt.\% Mg, 0.19 wt.\% Sc, 0.14 wt.\% Zr, 0.16 wt.\% $\mathrm{Mn}, 0.11$ wt. $\% \mathrm{Si}$ and 0.21 wt.\% Fe was studied after different casting conditions. Firstly, the material was twinroll cast in laboratory conditions on a vertical twin-roll caster [19] to thickness of $5 \mathrm{~mm}$. Afterwards, the material was subjected to severe plastic deformation by equal channel angular pressing -4 passes by route $B_{C}$ [12] at $250{ }^{\circ} \mathrm{C}$, sample size $5 \times 5 \times 50 \mathrm{~mm}^{3}$.

For comparison, conventionally cast material was prepared and subsequently rolled to the same thickness as the TRC material $-5 \mathrm{~mm}$.

As a next step all materials were subjected to annealing for 8 hours at $300^{\circ} \mathrm{C}$ in order to form $\mathrm{Al}_{3}(\mathrm{Sc}, \mathrm{Zr})$ particles. The most suitable conditions for the precipitation annealing were found during the preceding research, see $[20]$ for details.

The differences in the microstructure of the asprepared materials were observed by electron backscatter diffraction (EBSD) in scanning electron microscope (SEM) FEI Quanta 200 FX FEG and by transmission electron microscope (TEM) JEOL 2000FX. The EBSD data were analyzed by OIM software.

Materials were subjected to long term heating at $120^{\circ} \mathrm{C}$ in an air furnace to simulate the conditions to which the airplanes may be exposed. The electrical resistivity of the samples at temperature of liquid nitrogen $(77 \mathrm{~K})$ was measured during the heating and compared with the initial values. The fourpoint resistivity measurement on home-made apparatus equipped with Keithley instruments was applied [21]. After 80 days of the exposure to the elevated temperature the TEM specimens were prepared and the microstructure of the materials was compared.

\section{Results and discussion}

The manufacturing method has a significant influence on the microstructure of the final material. The conventionally cast and rolled material has pancakeshaped elongated grains (length in the rolling direction $\sim 200 \mu \mathrm{m}$, width in the transversal direction $\sim 50 \mu \mathrm{m}$ and thickness in the normal direction $\sim 5 \mu \mathrm{m}$ ) segmented into numerous subgrains. The twin-roll cast material possesses microstructure with relatively equiaxed grains of much larger grain size $(\sim 50 \mu \mathrm{m})$ than the conventionally cast material - Fig. 1. Moreover, the distribution of the primary particles is very different - more information about the differences between conventionally cast and twin-roll cast materials can be found in our previous work [16].

After the ECAP processing the equiaxed coarse grained structure of the twin-roll cast material is fragmented into inhomogeneous structure with fine (sub)grains around $2 \mu \mathrm{m}$ in diameter and elongated grains, inclined due to the ECAP deformation in the shearing direction [12].

Figure 2 depicts the details of the microstructure in the TEM. These confirm that the twin-roll cast material has much larger (sub)grain size than those processed by ECAP or prepared by conventional casting and rolling. The twin-roll cast material has a relatively low dislocation density. Deformation by ECAP leads to the formation of micron-size (sub)grains, partially surrounded by high angle grain boundaries. However, the microstructure is not uniform - partial elongation of the subgrains is apparent. Concerning the material prepared by conventional casting, due to the rolling part of the fabrication process the grains are fragmented into high amount of subgrains which are elongated in the rolling direction and contain high density of dislocations.
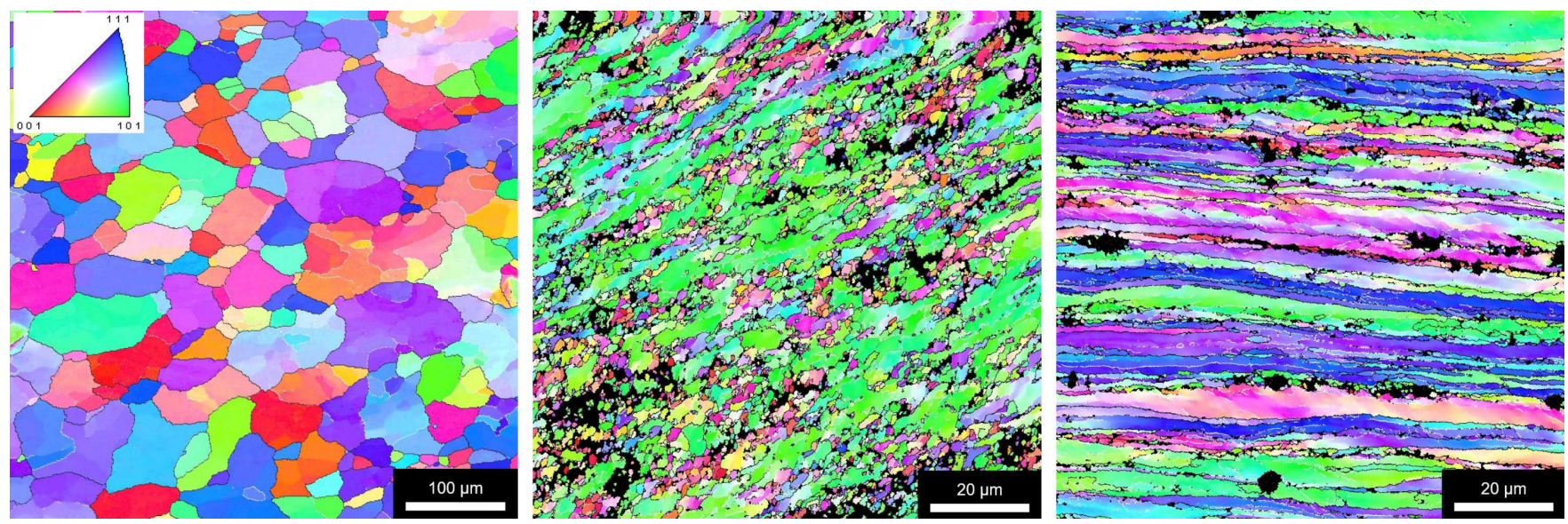

Fig. 1. EBSD orientation maps of as-cast grain structures - twin-roll cast material (left), processed by equal channel angular pressing (middle) and conventionally cast and rolled material (right). The rolling direction is horizontal for all materials. 

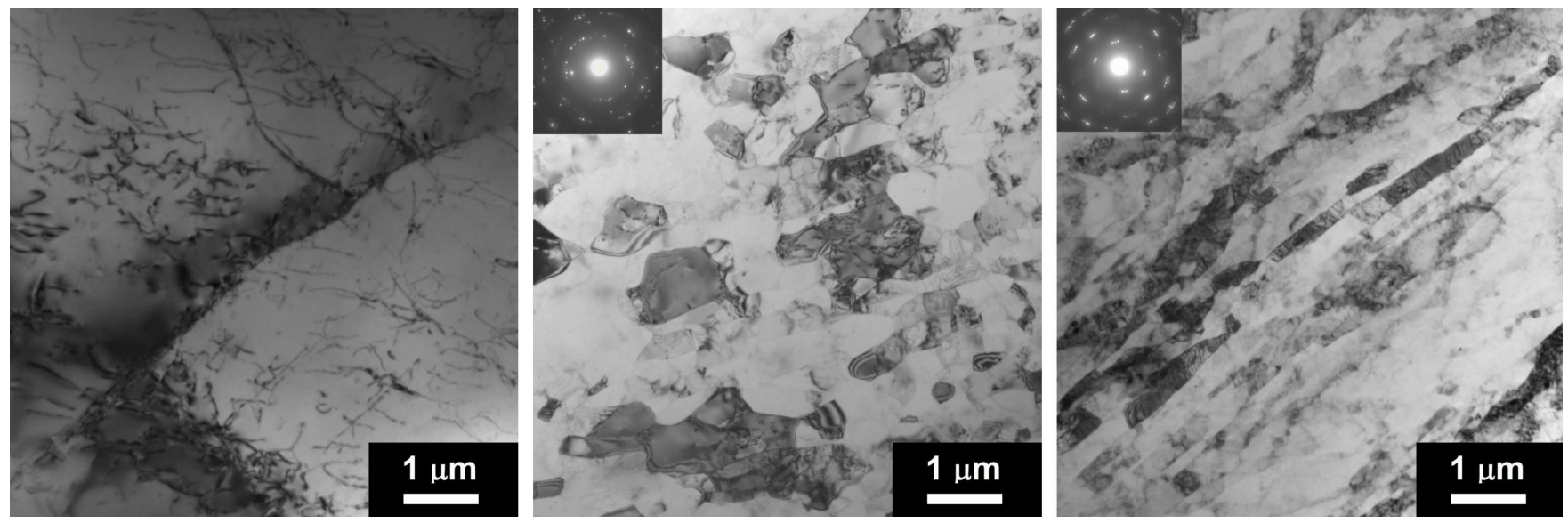

Fig. 2. Details of the microstructure in TEM - twin-roll cast material (left), processed by equal channel angular pressing (middle) and conventionally cast and rolled material (right).

The role of the three different microstructures on the material performance was further studied. All materials were subjected to heat treatment at $300^{\circ} \mathrm{C}$ in order to form coherent $\mathrm{Al}_{3}(\mathrm{Sc}, \mathrm{Zr})$ particles. More information about formation of these particles and their influence on the behavior of the studied material can be found in $[22,23]$. After annealing for 8 hours at $300^{\circ} \mathrm{C}$ the materials were exposed to a long term annealing at $120{ }^{\circ} \mathrm{C}$ during which the precipitation of $\beta$-phase $\mathrm{Al}_{3} \mathrm{Mg}_{2}$ was monitored.

Firstly, the electrical resistivity was progressively measured during the annealing and relative changes of the resistivity were plotted - see Fig. 3. Generally, the changes of the electrical resistivity are sensitive mainly to the redistribution of the solutes within the solid solution - precipitation leads to a decrease in resistivity, dissolution of the particles results in a resistivity increase (see e.g. [24]). As the measurement was conducted in the bath of liquid nitrogen, changes due to the thermal motion of the lattice may be neglected. The most significant resistivity decrease was registered in the conventionally cast and rolled material, after approximately 2000 hours of annealing the resistivity decreased by nearly $10 \%$. The change in the material processed by ECAP after the same time period was around $6 \%$ and the resistivity changes in the twin-roll cast material were quite moderate compared to the other two materials.

Subsequently, TEM specimens were prepared after 80 days of exposure at $120^{\circ} \mathrm{C}$ to evaluate the extent of $\mathrm{Al}_{3} \mathrm{Mg}_{2}$ precipitation, which was the expected reason for the observed resistivity decrease. The $\beta$-phase particles were observed both in the twin-roll cast and ECAPed materials (Fig. 4). They appeared mainly at the primary particles (this was also reported in work of Yan [9]) and also randomly on the grain boundaries between aluminium grains. They formed rather globular particles. The most severe segregation was detected in the conventionally cast material. There the $\beta$-phase particles formed not only the globular particles, but mainly nar- row chains along grain boundaries (Fig. 4), which are the most detrimental for the corrosion resistance of the material - microstructure with boundaries decorated by this type of particles is the most susceptible to the exfoliation corrosion.

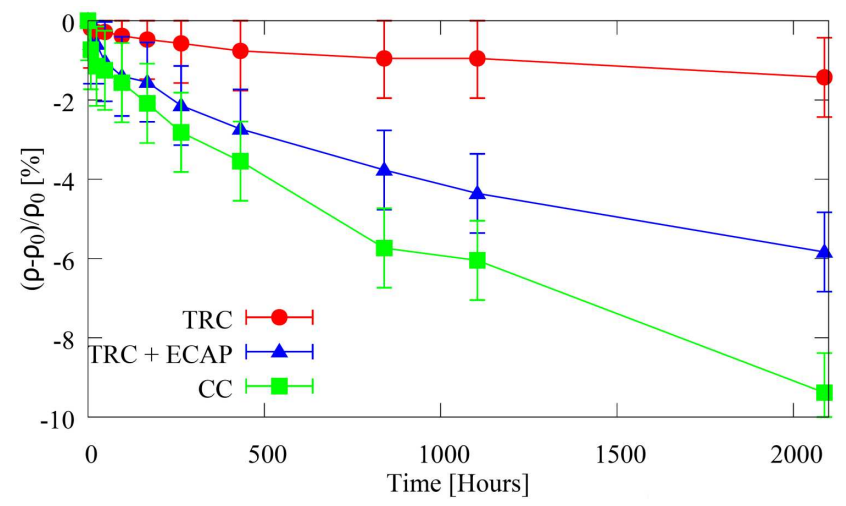

Fig. 3. Relative changes of electrical resistivity during annealing at $120^{\circ} \mathrm{C}$.

As the precipitation of the $\mathrm{Al}_{3} \mathrm{Mg}_{2}$ phase was reported to be dependent on the nature of the grain boundaries in the material $[5,6,8,9]$, the distribution of the misorientation angles higher than $5^{\circ}$ was calculated from the EBSD orientation maps and plotted in Fig. 5. The processing route has a significant influence on the misorientation distribution - the TRC material has much lower population of low angle grain boundaries $\left(\leq 15^{\circ}\right)$ than the conventionally cast and rolled material, whereas the high angle grain boundaries between $40-50^{\circ}$ have a twice higher number fraction than the boundaries of the conventionally cast material. According to work of D'Antuono [5] initial $\beta$-phase formation occurs more readily at low-angle grain boundaries - this explains the much higher resistivity decrease in the $\mathrm{CC}$ material and almost no decrease in the TRC material (Fig. 3), as the density of the newly formed $\mathrm{Al}_{3} \mathrm{Mg}_{2}$ particles is much lower in the TRC material. 

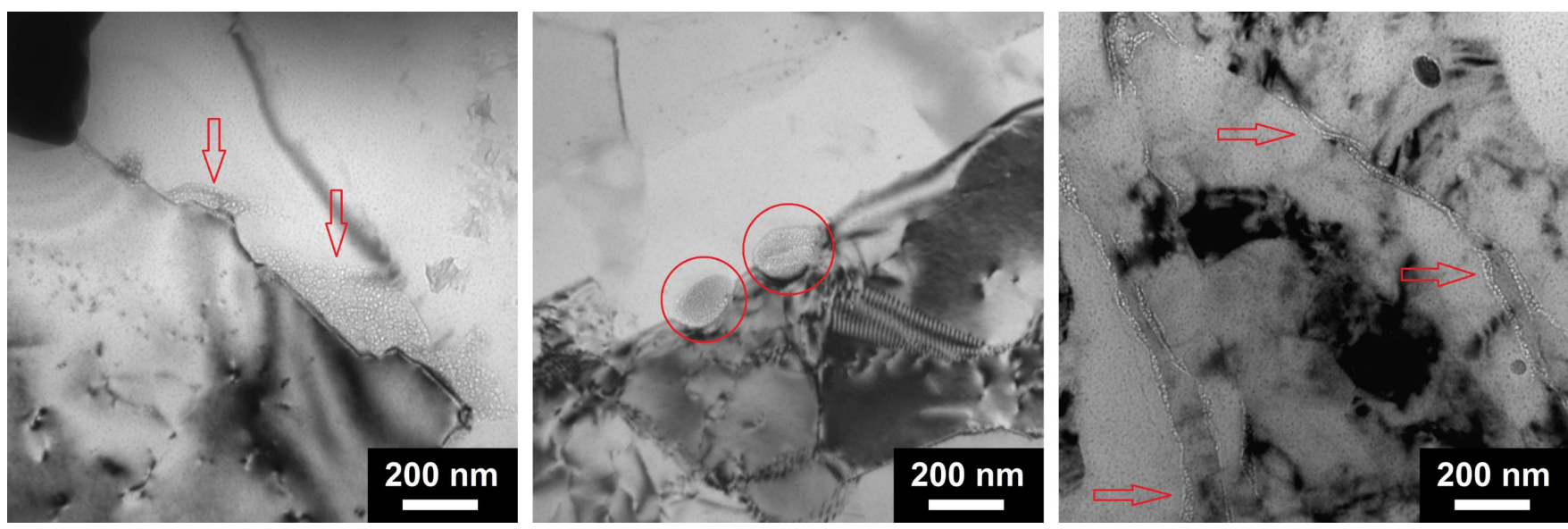

Fig. 4. The TEM images of the microstructure after annealing at $120^{\circ} \mathrm{C}$ for 80 days. Globular $\beta$-phase is formed in the twin-roll cast (left) and ECAPed (middle) materials, whereas, in the conventionally cast and rolled material (right) it decorates the (sub)grain boundaries in chains.

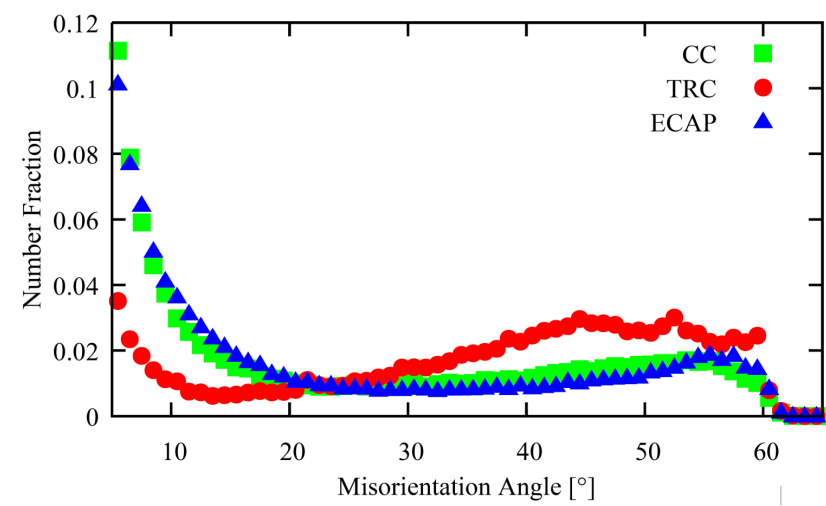

Fig. 5. Distribution of the misorientation angles in the range $5-65^{\circ}$.

Moreover, the dislocation density in the material was reported [8] to be correlated with the number of the $\mathrm{Al}_{3} \mathrm{Mg}_{2}$ particles and the CC material contains much higher dislocation density than the TRC material. Processing by ECAP leads to fragmentation of the grains (Fig. 1) and overall change of the misorientation distribution which approaches the one after conventional casting (Fig. 5). This results in a more pronounced decrease of the resistivity of the material after ECAP as compared to the TRC material. However, the shape and the distribution of the $\mathrm{Al}_{3} \mathrm{Mg}_{2}$ particles in the ECAPed material is much more random and preferable than in the conventionally cast and rolled material - it does not form continuous layer along the (sub)grain boundaries, thus formation of these particles should not be so detrimental for the material properties as in the case of the conventionally prepared one.

\section{Conclusion}

In material prepared by conventional casting and rolling a pancake grain structure with high dislocation density and high fraction of low angle grain boundaries forms. If such a material is exposed to temperature $120^{\circ} \mathrm{C}$ for a long term, the precipitation of $\beta$-phase layers on the (sub)grain boundaries occurs. Due to this particles the material may be more susceptible to exfoliation corrosion.

An alternative casting method - twin-roll casting changes significantly the grain structure and suppresses the formation of the $\beta$-phase. Further processing of the material by equal-channel angular pressing leads to the development of a different grain distribution. Although due to the higher dislocation density and fraction of low angle grain boundaries the precipitation extent of the $\beta$ phase is higher than in the as-received and annealed twinroll cast material, the $\beta$-phase forms in globular particles, which are not so detrimental for the corrosion resistance of the material.

\section{Acknowledgments}

The work was supported by Czech Science Foundation project 16-16218S and SVV-2017-260442.

\section{References}

[1] S. Lee, A. Utsunomiya, H. Akamatsu, K. Neishi, M. Furukawa, Z. Horita, T. Langdon, Acta Mater. 50, 553 (2002).

[2] Y. Deng, Z. Yin, K. Zhao, J. Duan, Z. He, J. Alloys Compd. 530, 71 (2012).

[3] V. Fallah, D.J. Lloyd, M. Gallerneault, Mater. Sci. Eng. A 698, 88 (2017).

[4] D. Yuzbekova, A. Mogucheva, R. Kaibyshev, Mater. Sci. Eng. A 675, 228 (2016).

[5] D.S. D'Antuono, J. Gaies, W. Golumbfskie, M. Taheri, Scr. Mater. 76, 81 (2014).

[6] Y. Zhao, M.N. Polyakov, M. Mecklenburg, M.E. Kassner, A.M. Hodge, Scr. Mater. 89, 49 (2014).

[7] Y. Peng, S. Li, Y. Deng, H. Zhou, G. Xu, Z. Yin, Mater. Sci. Eng. A 666, 61 (2016).

[8] D.S. D'Antuono, J. Gaies, W. Golumbfskie, M. Taheri, Acta Mater. 123, 264 (2017). 
[9] J. Yan, A.M. Hodge, J. Alloys Compd. 703, 242 (2017).

[10] C.B. Fuller, D.N. Seidman, D.C. Dunand, Acta Mater. 51, 4803 (2003).

[11] M. Vlach, J. Čížek, B. Smola, O. Melikhova, M. Vlček, V. Kodetová, H. Kudrnová, P. Hruška, Mater. Charact. 129, 1 (2017).

[12] R.Z. Valiev, T.G. Langdon, Prog. Mater Sci. 51, 881 (2006).

[13] Y. Birol, J. Alloys Compd. 471, 122 (2009).

[14] C. Gras, M. Meredith, J.D. Hunt, J. Mater. Process. Technol. 169, 156 (2005).

[15] M. Slámová, M. Karlík, F. Robaut, P. Sláma, M. Véron, Mater. Charact. 49, 231 (2002)

[16] M. Šlapáková, B. Křivská, J. Bajer, O. Grydin, M. Cieslar, Manufacturing Technology 18, 130 (2018).

[17] N. Sun, B.R. Patterson, J.P. Suni, E.A. Simielli, H. Weiland, L.F. Allard, Mater. Sci. Eng. A 416, 232 (2006).
[18] W.C. Liu, T. Zhai, J.G. Morris, Scr. Mater. 51, 83 (2004).

[19] M. Stolbchenko, O. Grydin, M. Schaper, Materials Today: Proceedings 2, S32 (2015), MEFORM 2015.

[20] M. Cieslar, J. Bajer, M. Šlapáková, B. Křivská, M. Zimina, O. Grydin, Acta Phys. Pol. A 134, 145 (2018).

[21] M. Hájek, J. Veselý, M. Cieslar, Mater. Sci. Eng. A 462, 339 (2007).

[22] B. Křivská, M. Šlapáková, J. Bajer, O. Grydin, M. Cieslar, Acta Phys. Pol. A 134, 895 (2018).

[23] M. Cieslar, J. Bajer, M. Zimina, M. Šlapáková, O. Grydin, IOP Conf. Series: Mater. Sci. Eng. 179, 012012 (2017).

[24] M. Poková, M. Cieslar, M. Slámová, Int. J. Mater. Res. 100, 391 (2009). 